\title{
AS NORMAS NACIONAIS E INTERNACIONAIS SOBRE IMIGRAÇÃO NA América do Sul e SUA RePerCuSSão nOS FluXos Migratórios REgIONAIS
}

\author{
The national and international rules on immigration in South America and \\ its impact on the regional migration flows
}

\section{Vanessa Oliveira Batista}

Professora Associada da Faculdade Nacional de Direito. Professora do Programa de Pós-Graduação em Direito da UFRJ. Pesquisadora do CNPq. Coordenadora do Laboratório de Direitos Humanos da UFRJ. E-mail: vanessabberner@gmail.com

\section{Carolina Genovez Parreira}

Mestranda do Programa de Pós-Graduação em Direito da UFRJ. Graduada em Direito. Pesquisadora do Laboratório de Direitos Humanos da UFRJ. E-mail: carolinagenovez@gmail.com

RECEBIDO EM: 03.03.2013

APROVADO EM: 01.06.2013

\section{Resumo}

O aumento na intensidade dos fluxos migratórios humanos pode ser observado desde o advento da modernidade, e cada vez mais pessoas procuram melhores condições de vida em outros países quando seu bem-estar se encontra ameaçado. No caso do subcontinente sul-americano cada vez mais tem crescido a imigração dentro da região e a tendência dos países de destino é de adotar medidas cada vez mais restritivas para impedir a entrada desses imigrantes, contrariando os catálogos normativos dos direitos humanos. O presente trabalho visa a analisar a situação migratória dos países nessa região e a investigar as legislações vigentes sobre o assunto.

Palavras-chave: Direito da Imigração. América do Sul. Direito Comparado.

\section{Abstract}

The increase in the intensity of human migration can be observed since the advent of modernity, and more and more people seek a better life in other countries when their welfare is threatened. In the case of the South American subcontinent 
it has increasingly in the regional level and there is a tendency of the destination countries to adopt measures more and more restrictive to prevent the entry of those immigrants, contradicting, in that way, the catalogs of human rights norms. This present work aims to analyze the migratory situation in the region and investigate existing laws on the subject.

Keywords: Immigration Law. South America. Comparative Law.

SumÁrio: Introdução. 1. A imigração intrarregional. 2. Imigrantes brasileiros na América do Sul. 3. Acordos sobre o fluxo de pessoas no MERCOSUL . Conclusão. Referências.

\section{INTRODUÇÃo}

A migração é o movimento de entrada de pessoas, com ânimo permanente, de um país para outro, ocorrendo geralmente por iniciativa própria, tendo como objetivo diversos motivos, como melhores condições de vida e de trabalho. Esse deslocamento pode também ocorrer por motivos alheios à vontade do imigrante. $\mathrm{O}$ presente trabalho irá se focar, somente, na migração voluntária.

Com todos os problemas sociais, climáticos, econômicos e políticos que acontecem no mundo, cada vez mais pessoas saem do seu Estado de origem para buscarem melhores condições de vida, ou para fugirem de situações perigosas como guerra civil ou perseguição política. Porém, a política atual dos países é de criar leis cada vez mais restritivas, visando frear os fluxos migratórios, e principalmente a entrada de indivíduos que não configuram uma mão de obra com alto conhecimento técnico.

No Brasil, a imigração foi fundamental para a colonização do país e para a sua formação cultural e econômica, tendo sido usada para a proteção e exploração do território brasileiro após o descobrimento. Naquele período ocorreu a imigração em massa de portugueses, que vieram para o Brasil ocupar a terra recém descoberta. Mais tarde é possível se verificar a imigração de italianos, alemães, suíços, árabes, chineses e atualmente, aumenta o número de imigrantes provenientes dos países da América Latina.

A América Latina é, historicamente, uma das regiões com os fluxos migratórios mais intensos, especialmente em direção aos países desenvolvidos do Norte. Ultimamente, entretanto, com o endurecimento das políticas migratórias do Estados Unidos da América, Japão e dos países da Europa, e em virtude da crise econômica que afeta aqueles países, os fluxos migratórios da região tem sofrido grande impacto. Conforme dados demográficos, boa parte dos imigrantes latino-americanos escolhe imigrar para países vizinhos, dentro da própria região, sendo que na América do Sul 
os destinos preferenciais são Argentina, Venezuela e Brasil.

O presente trabalho tem como objetivo principal apresentar o atual fenômeno migratório na América do Sul, com foco nos imigrantes da região que se encontram no Brasil e nos brasileiros residentes em países vizinhos, como Paraguai e Bolívia, analisando a regulamentação jurídica dessas migrações na região, efetuada por meio de acordos migratórios no plano regional que influenciam esses movimentos humanos.

\section{A IMigraÇão intrarregional}

A imigração intrarregional na América Latina aumentou nos últimos anos em decorrência de fatores como a maior facilidade de conseguir emprego, a identificação cultural, a facilidade de compreensão do idioma e, principalmente, o crescimento econômico dos países da região em decorrência de sua maior integração. Segundo Juan Artola, diretor da Organização Internacional de Migração (OIM) para América do Sul, há uma tendência ao crescimento da imigração regional em detrimento da imigração de sul-americanos para os países da Europa e dos Estados Unidos que eram, até pouco tempo atrás, os principais destinos dos imigrantes latino -americanos. Isto ocorre principalmente em função da dificuldade que os imigrantes enfrentam para conseguir um visto permanente nos países desenvolvidos. Para Artola, "essa imigração intrarregional é um fato inédito nos últimos 30 ou 40 anos, mas coincide com o crescimento econômico e o impulso do processo de integração do MERCOSUL e da ALADI (Associação Latino-Americana de Integração)" (CARMO, 2012).

$\mathrm{Na}$ verdade, essa imigração fronteiriça vem ganhando grande expressividade desde 1950, em decorrência do processo de industrialização do Brasil e Argentina, cuja grande expansão econômica contrastava com o baixo crescimento econômico ou a recessão nos países vizinhos. Além disso, a partir daquela década, se estabeleceram regimes ditatoriais em diversos países latino-americanos, inclusive no Brasil. Para alguns autores, o principal motivo do aumento da imigração de fronteira seria, sobretudo, a existência de traços culturais e socioeconômicos em comum, o que facilitaria a assimilação dos imigrantes de países vizinhos (SILVA, 1997).

Embora em termos econômicos o Brasil apresente uma posição de destaque na região, ele é apenas o terceiro principal destino dos imigrantes latino-americanos, atrás da Argentina e da Venezuela. Os imigrantes que se instalam em território brasileiro são, em sua maioria, oriundos da Bolívia, do Paraguai, do Peru e do Equador. (Anexo A). Segundo o Ministério do Trabalho, havia no Brasil cerca de 180 mil imigrantes em situação irregular em 2008, sendo essa estimativa bem menor que a feita pelo Serviço Pastoral dos Migrantes, orgão ligado à Conferência Nacional dos Bispos do Brasil, que estima que existam pelo menos 600 mil imigrantes ilegais, a maioria formada por imigrantes latino-americanos, principalmente bolivianos, pa- 
raguaios, peruanos, chilenos, argentinos e colombianos (CARMO, 2008). Uma das causas desse elevado número de imigrantes indocumentados é a política migratória brasileira, voltada para a captação de mão de obra qualificada e para investidores que demonstrem capacidade para criar mais vagas de emprego para nacionais. É interessante observar que embora a legislação brasileira (Lei ${ }^{\circ}$ 6.815/80 - Estatuto do Estrangeiro) não defina a 'substituição de mão de obra nacional', as autoridades brasileiras têm concedido vistos permanentes para estrangeiros mais qualificados profissionalmente, e negado vistos aos que caracterizem, justamente 'a substituição de mão de obra nacional' (!), o que significa que a ficando essa interpretação do texto legislativo fica ao sabor da discricionariedade das autoridades estatais.

Vale mencionar que o Estatuto do Estrangeiro impõe uma série de restrições aos estrangeiros e garante poucos direitos. Entre as restrições, os imigrantes não podem ser proprietários, comandantes ou armadores de navio nacional, embora o possam ser de uma embarcação de bandeira estrangeira em serviço ou em trânsito no Brasil. Também é vedada ao estrangeiro a propriedade de empresa jornalística, de empresas de televisão e de radiodifusão, assim como ser sócio ou acionista de sociedade proprietária dessas empresas, além de não poder ser seu responsável, orientador intelectual ou administrativo e não poder possuir, manter ou operar, mesmo como amador, aparelho de radiodifusão, de radiotelegrafia e similar. Os estrangeiros não podem, ainda, obter concessão ou autorização para a pesquisa, exploração e aproveitamento das jazidas, minas e demais recursos minerais e dos potenciais de energia hidráulica. O art. 107 do Estatuto do Estrangeiro e o art. 14 da Constituição Federal de 1988 negam direitos políticos aos imigrantes, não podendo os estrangeiros votarem ou se candidatarem a cargo público, além de não poderem organizar, criar ou manter qualquer organização de caráter político.

Devido às restrições legais de acesso, os imigrantes acabam entrando no Brasil por meios clandestinos ou recorrendo a intermediários que os trazem para o país por uma alta quantia de dinheiro. São os chamados "gatos" ou "coiotes". Há ainda aqueles que trazem os imigrantes de forma irregular para trabalharem em determinada empresa em situações análogas à escravidão. Muitas vezes, essa dificuldade de entrar no país transforma o imigrante em vítima de redes de tráfico de pessoas, podendo ser enganados por traficantes que os fazem crer numa perspectiva de trabalho melhor do que aquela a que serão verdadeiramente submetidos. Na Bolívia, jornais publicam anúncios de emprego com boas condições de trabalho em fábricas de costura no Brasil, especificamente em São Paulo. Muitos chegam a anunciar que o contrato de trabalho inclui a moradia e a alimentação sem custos adicionais, o que acaba não sendo a realidade na maioria dos casos (BAENINGER, 2020).

No caso brasileiro, segundo o censo do Instituto Brasileiro de Geografia e Estatísticas (IBGE) realizado no ano de 2000, residiam no país naquela ocasião cerca de 279 mil imigrantes regulares, sendo 116 mil provenientes de países da América do Sul. A grande maioria dos imigrantes sul-americanos que se encontra no Brasil, está 
concentrada nos estados do Mato Grosso do Sul, Paraná, Santa Catarina, Rio Grande do Sul, São Paulo e Rio de Janeiro (Anexo B).

Já o último censo brasileiro, realizado em 2010, mostra que a maior parte dos imigrantes residentes no Brasil é proveniente, respectivamente, da Bolívia (11.798 pessoas), Paraguai (10.918 pessoas), Estados Unidos (8.212 pessoas) e Argentina (5.254 pessoas). Residem hoje no país, segundo o IBGE, 93.889 mil imigrantes, dos quais 41.318 mil são latino-americanos.

Grande parte dos imigrantes latino americanos em situação irregular no país trabalha em confecções nos bairros de Brás, Pari, Bom Retiro, e no centro de São Paulo, em jornadas abusivas de até dezoito horas diárias de segunda à sábado. Os seus passaportes são apreendidos até que quitem suas dívidas com os patrões, provenientes do custo da alimentação, moradia, ferramentas para o trabalho e, no caso de estrangeiros recrutados pelos empregadores nos seus países de origem, eles também devem arcar com o custo da viagem. Essa dívida aumenta cada vez mais e a maioria nunca consegue pagar o que deve, vivendo numa situação de escravidão por dívida. Como exemplo dessa exploração, podem ser apontados os imigrantes bolivianos que trabalhavam numa oficina ligada à loja de roupas 'Marisa'. No local, foram encontrados sete trabalhadores e uma criança em um lugar úmido e sem circulação de ar, que estavam em cárcere privado devido a dívida de alto valor, sendo-lhes cobrada desde a comida e luz, até o equipamento para o trabalho e a travessia pela fronteira, numa clara situação de aliciamento de mão de obra (HASHIZUME, 2010).

Outro caso parecido foi o da loja de roupas 'Zara', que pertence ao grupo espanhol Inditex. Equipes de fiscalização da Superintendência Regional do Trabalho e Emprego de São Paulo (SRTE/SP) encontraram, em uma das fornecedoras da marca, imigrantes bolivianos e peruanos trabalhando em condições análogas à escravidão. Na oficina, localizada na cidade de São Paulo, estavam 15 pessoas, incluindo uma adolescente de 14 anos de idade. Eles eram submetidos a jornadas exaustivas de até $16 \mathrm{~h}$ diárias e cerceamento de liberdade pela proibição de deixar a oficina sem prévia autorização do dono, o que só acontecia, segundo os trabalhadores, em 'casos urgentes' (HASHIZUME, 2011)

As oficinas em que esses imigrantes trabalham normalmente operam cheias de empregados, com pouca iluminação e ventilação, o que prejudica a saúde desses trabalhadores, sendo que a instalações muitas vezes também servem de moradia para os imigrantes e suas famílias, pois eles não têm dinheiro para arcar com um aluguel. Deve-se mencionar que muitas vezes essas oficinas exploram o trabalho infantil, pois para complementar a renda familiar as mulheres e as crianças são obrigadas a trabalhar, mesmo em condições insalubres. Essas relações de trabalho, absolutamente ilegais, sujeitam o trabalhador estrangeiro a condições extremamente precárias e a situações análogas à escravidão. A grande maioria desses imigrantes não tem acesso a justiça trabalhista pelo medo sempre presente da deportação.

O elevado número de imigrantes em situação irregular levou o governo 
brasileiro a conceder anistias que permitem ao estrangeiro, sem o pagamento de multas e penalidades, pedir sua permanência provisória por dois anos e depois requerer a transformação de seus registros temporários para permanentes. Com a anistia, os imigrantes irregulares passam a ter direitos equivalentes aos do brasileiro, incluindo moradia, acesso à saúde e à educação. Não podem, no entanto, ter direitos políticos, havendo ainda outras vedações contidas no Estatuto do Estrangeiro.

Foram concedidas quatro anistias pelo governo brasileiro: em 1981, 1988, 1998 e 2008. Focando nas duas últimas, os dados disponíveis demonstram que, na anistia concedida em 1998, um total de 40.909 estrangeiros regularizaram a sua situação na Polícia Federal, sendo desse total, 9.155 bolivianos, 3.177 argentinos, 2.703 uruguaios, 2.320 peruanos, 1.784 chilenos, 1.156 paraguaios, ou seja, cerca de $50 \%$ do número de imigrantes irregulares que conseguiram o seu registro temporário eram provenientes de países da América Latina. Já em 2008, essa porcentagem aumenta para quase $60 \%$, pois dos 43 mil estrangeiros regularizados, 16.881 imigrantes eram bolivianos 4.642 peruanos e 4.135 paraguaios (BORGES, 2010).

\section{Imigrantes brasileiros na América do Sul}

Embora o Brasil tenha sido historicamente um país de imigração, desde 1980 os brasileiros têm feito parte desse movimento migratório internacional, apresentando, hoje, um saldo migratório negativo. Nesse período, a chamada Década Perdida trouxe desemprego e altos índices de inflação, criando uma situação de crise econômica extrema, o que acabou levando muitos brasileiros a procurarem melhores condições de vida em outros países.

Segundo dados oficiais do Ministério das Relações Exteriores, estima-se que, em 2011, viviam no exterior mais de três milhões de brasileiros, sendo os principais países de destinos os Estados Unidos, Paraguai e Japão. Nos últimos anos, porém, o número de brasileiros que imigram para países da América Latina vem crescendo e, segundo relatório elaborado pelo Ministério das Relações Exteriores em julho de 2011, hoje residiriam cerca de 400 mil brasileiros nos países da América do Sul, embora esses dados não incluam a maioria dos imigrantes que vivem hoje em situação irregular, principalmente se considerar que a maioria dos imigrantes irregulares não procura os órgãos oficiais com medo de ser deportada. (Anexos C e D)

A grande maioria dos imigrantes brasileiros se encontra concentrada no $\mathrm{Pa}$ raguai, embora exista uma expressiva quantidade residente na Bolívia e no Peru ${ }^{414}$. Houve uma mudança de destino dos fluxos de imigrantes brasileiros, aparentemente motivada pelas legislações vigentes nos sul-americanos, que se caracterizam por serem mais liberais que as políticas migratórias adotadas pelos países da Europa e pelos Estados Unidos.

Calcula-se que, atualmente, mais de duzentos mil brasileiros residem em

414 Estima-se que 60 mil brasileiros residam na Bolívia e no Peru. 
países vizinhos, especialmente no Paraguai, na Argentina, na Bolívia e no Uruguai - todos eles países membros ou associados do Mercado Comum do Sul (MERCOSUL). Tal quantidade converte o Brasil no quinto maior emissor intrarregional de imigrantes. Os maiores emissores de imigrantes para países da região sul americana são: Colômbia (600 mil imigrantes), Paraguai (280 mil imigrantes), Chile (260 mil imigrantes) e Bolívia (210 mil imigrantes) (BAENINGER, 2002).

Mais da metade dos brasileiros residentes na América Latina se encontra no Paraguai. Trata-se de pelo menos 150 mil pessoas - freqüentemente chamadas "brasiguaios". Esse importante contingente de brasileiros residentes em território paraguaio consolidou sua presença durante a década de 1970. Na época, os brasiguaios foram atraídos pela oferta de terras férteis com preços muito mais baratos que do lado brasileiro da fronteira comum (pull effect), bem como chegaram à fronteira para participar da construção da barragem binacional de Itaipu, instalando-se ali a fim de conseguir melhores condições de vida. De fato, depois de muitos esforços, um considerável número de brasileiros residentes no Paraguai logrou prosperar no agronegócio, destacando-se pela massiva produção de soja para exportação.

Segundo o Ministério das Relações Exteriores do Paraguai, em 2002 viviam no Paraguai 459.147 mil brasileiros, muitos em situação irregular. Já o Ministério das Relações Exteriores brasileiro, em relatório elaborado em 2011, estima que seriam cerca de 200 mil brasileiros. Nos anos recentes, a situação migratória dos brasileiros residentes no Paraguai tem se caracterizado por uma crescente tensão. Especialmente preocupantes são os frequentes questionamentos e ataques a latifundiários brasileiros por parte do Movimento dos Trabalhadores Rurais Sem Terra do Paraguai. Tais divergências, acrescidas da presença de um expressivo número de brasileiros indocumentados, tem despertado a atenção dos governos e sociedades de ambos os países. Ademais, milhares de trabalhadores brasileiros que vivem na cidade de Foz do Iguaçu, se deslocam diariamente para trabalhar na Cidade de Leste, especialmente nas atividades comerciais, constituindo-se em importantíssima comunidade dedicada à reexportação de bens e serviços para o mercado brasileiro.

No que diz respeito à Bolívia, a imigração dos brasileiros se faz notar na década de 1980, estimulada pela busca de terras - mais caras no Brasil - como acontece com os brasileiros no Paraguai. Hoje a Bolívia conta com a segunda maior comunidade de brasileiros na América do Sul, embora ainda seja quatro vezes menor que o contingente detectado no Paraguai. Uma parte desses imigrantes procurou se estabelecer no país em áreas rurais, adquirindo terras para cultivo nas cidades de Beni, Pando, Tarija e Santa Cruz, havendo muitos proprietários rurais de grande e médio porte, normalmente plantadores de soja, ajudando a economia boliviana através da exportação da soja. Calcula-se que mais de 25 mil brasileiros se dediquem às atividades agropecuárias no território boliviano (AVILA, 2007).

Entretanto, a maioria dos imigrantes brasileiro residentes na Bolívia, hoje, tem um baixo grau de instrução e vive em cidades fronteiriças com os estados do 
Acre, Rondônia e Mato Grosso, trabalhando com a extração da borracha e da castanha. No caso da extração vegetal, a maioria desses imigrantes está trabalhando ilegalmente em seringais e castanhais, pois segundo a Constituição Boliviana é proibido o trabalho de estrangeiros dentro de seu território num raio de aproximadamente $50 \mathrm{~km}$ próximo à fronteira, o que os leva a ter uma baixa qualidade de vida. A presença estrangeira nessas áreas desencadeou muitos conflitos na região desde a crise da borracha em 1980, o que levou os bolivianos a começaram a protestar pela saída dos brasileiros de seu território.

Além disso, ainda encontramos muitos brasileiros que vão para a Bolívia cursar medicina nas universidades, uma vez que lá não é necessário prestar o vestibular. Cerca de cinco mil estudantes entraram na Bolívia em 2010 para estudar.

Sobre a imigração no Peru, segundo estatísticas oficiais do INEI (Instituto Nacional de Estatística e Informática) mais de 3.000 brasileiros vivem em caráter permanente no país, a sexta maior população imigrante no país, sendo que, a cada ano, entra no país uma média de 9.000 brasileiros $^{415}$. Destaque-se que a legislação peruana destaca-se por apresentar um grande avanço em matéria migratória. A Lei dos Estrangeiros peruana conceitua como estrangeiro todo aquele que não possui a nacionalidade peruana, sendo que cada pessoa representa uma unidade migratória que será composta por ele, seu cônjuge, os filhos menores, filhas solteiras, pais e dependentes, tendo sua qualidade de imigrante entendida a todos eles ${ }^{416}$. A Lei de Nacionalidade Peruana e seu Regulamento tratam tanto da aquisição da nacionalidade originária quanto do processo de naturalização. Essa lei dispõe que podem requerer a naturalização todos os estrangeiros que residirem no país por, no mínimo, dois anos consecutivos, período bem menor que os quinze anos exigidos pela Constituição Brasileira. A lei peruana para Contratação de Estrangeiros, embora estabeleça a preferência pelo trabalhador nacional, dispões que as empresas nacionais poderão contratar estrangeiros, observadas as restrições legais, até $20 \%$ do total de seus funcionários. Os contratos, de três anos, pode ser renovados por igual período sucessivamente, conforme o prazo do contrato de trabalho. Por outro lado, a empresa contratante deve se comprometer a treinar e capacitar nacionais para as funções exercidas pelo estrangeiros, numa clara demonstração de que a contratação de imigrantes faz parte de uma politica atrelada ao desenvolvimento do país.

Segundo Hasenbalg e Frigerio (1999), a imigração brasileira na Argentina começa em 1869 quando foram contabilizados seis mil brasileiros vivendo no país. Entretanto, esse fluxo somente é expressivo a partir da década de 1970. A maioria dos brasileiros residentes no país vizinho está concentrada na região de Missiones e Buenos Aires. Os brasileiros estabelecidos em Missiones são, em geral, trabalhadores agrícolas com baixa escolaridade. Em Buenos Aires, os brasileiros trabalham

415 Disponível em: http://www.digemin.gob.pe/Informacion/Estadisticas/MOVMIG-EXTRANJEROS/ENT\%20Y\%20SAL\%20EXT\%202006.pdf .Acessado em: 15.06.2011.

416 Arts. 2 e 3 do Decreto Legislativo no 703 de 5 de novembro de 1991. 
no setor de serviços e, de acordo com os autores, "na região de Buenos Aires, os brasileiros exercem ocupações condizentes com o nível de instrução que possuem (e social)" (HASENBALG, FRIGERIO,1999).

Por outro lado, o contingente de brasileiros residentes no Uruguai é decrescente - cerca de 10 mil pessoas. Parte considerável dos brasileiros residentes no Uruguai é constituída por pessoas idosas e mulheres jovens. A maioria dos trabalhadores brasileiros nesse país concentra-se em atividades informais, na agricultura e no setor de serviços. Apenas uma pequena parcela desses imigrantes se dedica às atividades industriais.

\section{ACORdos SObre o FluXo de PESSOAS no MERCOSUL}

No âmbito do Pacto Andino (Bolívia, Equador, Peru, Colômbia, Venezuela) estão em discussão o Instrumento Andino de Migrações Trabalhistas (ou iniciativa 116) e o Instrumento Andino de Previdência Social, firmados ambos em 1977, afirmam, respectivamente, a preferência pelos trabalhadores migrantes da região e reconhecem os mesmos direitos sociais para nacionais ou imigrantes da região. As discussões apontam para a ampliação dos direitos dos trabalhadores no contexto regional, criando a figura do "trabalhador comunitário", que estaria dentro da perspectiva de aprofundamento da integração regional.

No âmbito do MERCOSUL existem vários acordos internacionais que dispõem sobre a circulação de pessoas e a mão de obra, sendo os principais: Acordo de Regularização Migratória entre Brasil e Bolivia; Declaração Sociolaboral do MERCOSUL; Acordo para Permissão de Residência; Estudo e Trabalho a nacionais Fronteiriços Brasileiros e Uruguaios; Acordo entre Brasil e Argentina sobre Localidades Fronteiriças Vinculadas; Acordo Multilateral de Seguridade Social do Mercado Comum do Sul; Acordo sobre Residência para Nacionais dos Estados Partes do Mercado Comum do Sul (MERCOSUL), Bolivia e Chile.

O Acordo de Regularização Migratória entre Brasil e Bolívia ${ }^{417}$ foi firmado em agosto de 2005 entre os governos Lula e Evo Morales, e trouxe aos imigrantes de ambos os países que ingressaram no território do outro país até 15/08/2005 a possibilidade de regularização migratória, com consequente possibilidade da melhoria das condições de vida. Para se regularizarem, entretanto, os imigrantes tiveram que arcar com altas taxas de inscrição e pagamento do INSS. Além disso, diante das dificuldades com o idioma e da falta de informações, muitos desses contrataram advogados, chegando a gastar até cinco mil reais cada. Além disso, os imigrantes tinham muita dificuldade em trazer os antecedentes da Bolívia, pois embora as autoridades bolivianas tivessem garantido que a Polícia Técnica boliviana - que expede as certidões de antecedentes - viria para o Brasil para fazer a expedição, a autoridade policial

417 Disponível em http:/www.mte.gov.br/trab_estrang/acordo.pdf. Acessado em: 12.09.2011. 
nunca apareceu e o consulado teve que nomear alguns bolivianos para buscar esses antecedentes.

O Acordo tinha vigência prevista de doze meses, mas foi prorrogado nos anos de 2006, 2007 e 2008. No entanto, o governo brasileiro, baseando-se na política de reciprocidade adotada pelo Ministério das Relações Exteriores (MRE), não renovou o acordo em 2009 alegando que o número de brasileiros que se regularizaram na Bolívia é pequeno em comparação com o número de bolivianos que se beneficiaram em território nacional, pois segundo dados do MRE, enquanto no Brasil cerca de 18 mil bolivianos regularizaram a sua situação através do acordo, na Bolívia foram somente cerca de 650 brasileiros regularizados.

No âmbito do MERCOSUL foi criado Subgrupo de Trabalho no 11 com a finalidade de analisar a questão trabalhista no MERCOSUL. Em dezembro de 1991, como resultado do estudo desenvolvido por este Subgrupo, detectou-se a necessidade da adoção de uma Carta de Direitos Fundamentais do MERCOSUL, o que levou à criação da Declaração Sociolaboral do bloco. Essa declaração estabelece diretrizes a serem observadas por todos os Estados Membros (artigo 20), dentre elas: a não discriminação e a promoção da igualdade; a eliminação do trabalho forçado; a liberdade sindical; a negociação coletiva; e o direito de greve.

A Declaração também dispõe que todo trabalhador tem garantida a igualdade de tratamento e oportunidades "sem distinção ou exclusão por motivos de raça, origem nacional, cor, sexo ou orientação sexual, idade, credo, opinião política ou sindical, posição econômica ou qualquer outra condição social ou familiar" 418 .

Sobre as garantias aos trabalhadores migrantes, a Declaração dispõe que eles tem direito a ajuda; informação; proteção e igualdade de direitos e condições de trabalho; além de estabelecer que os Estados Partes devem adotar medidas comuns relativas à circulação dos trabalhadores nas zonas de fronteira e planejar ações necessárias para melhorar as oportunidades de emprego e condições de trabalho e de vida desses trabalhadores ${ }^{419}$.

Sobre o Acordo para Permissão de Residência, Estudo e Trabalho a Nacionais Fronteiriços Brasileiros e Uruguaios ${ }^{420}$, este foi criado visando a estabelecer normas relativas aos indivíduos que exerçam atividade laboral nas cidades fronteiriças entre Brasil e Uruguai enumeradas no Acordo, permitindo que esses trabalhadores fixem residência na localidade vizinha à cidade situada no território do outro Estado Parte ${ }^{421}$, e que exerçam qualquer oficio ou profissão nessas localidades, com as consequentes obrigações e direitos previdenciários deles decorrentes, sendo-lhes concedido documento especial de 'Trabalhador Fronteiriço'.

418 Art. $1^{\circ}$ da Declaração Sociolaboral do MERCOSUL

419 Art. $4^{\circ}$ da Declaração Sociolaboral do MERCOSUL

420 Celebrado em 21 de agosto de 2002 e promulgado no Brasil pelo Decreto $\mathrm{n}^{\circ} 5.105$ de 14 de Junho de 2004

421 Denominadas no Acordo de Localidades Vinculadas. 
O Ajuste Complementar do Acordo permite a prestação de serviços de saúde por pessoas físicas ou jurídicas situadas nas cidades vizinhas estabelecidas no Acordo (Localidades Vinculadas), sendo os prestadores de saúde somente poderão admitir pacientes residentes nas zonas urbanas, suburbanas ou rurais de uma das Localidades Vinculadas ${ }^{422}$.

O Acordo entre Brasil e Argentina sobre Localidades Fronteiriças Vinculadas foi celebrado em 30 de novembro de 2005 e prevê a emissão de um documento para o trânsito vicinal, permitindo que brasileiros e argentinos residentes na fronteira tenham o livre acesso entre as cidades fronteiriças ${ }^{423}$ e que possam requerer a identificação de seus veículos para facilitar o tráfego. Além disso, ele permite que brasileiros e argentinos que vivem nessas cidades frequentem escolas e hospitais nos dois lados da fronteira. Os dois países ainda se comprometem, segundo o acordo, a promover o intercâmbio de professores, alunos e materiais educativos. O principal ponto do acordo é que as pessoas beneficiadas por ele poderão exercer profissão ou ofício do outro lado da fronteira sem precisar de visto, necessitando somente do documento de trânsito especial, além de terem garantidos seus direitos trabalhistas e previdenciários. Embora criado em 2005, o acordo só entrou em vigor com o Decreto Legislativo $\mathrm{n}^{\mathrm{o}} 145$ de 05/04/2011.

Quanto ao Acordo Multilateral de Seguridade Social do Mercado Comum do Sul, ele foi assinado em 15 de dezembro de 1997 e promulgado no Brasil pelo Decreto $\mathrm{n}^{\circ} 5.722$, de 13 de Março de 2006. O instrumento se constitui em importante passo para melhorar a condição de vida dos imigrantes provenientes do MERCOSUL, pois prevê que os direitos à seguridade social serão reconhecidos aos trabalhadores residentes em qualquer um dos Estados Membros, sendo garantidos os mesmos direitos e deveres aos nacionais e imigrantes de qualquer outra nacionalidade residentes no território de um dos Estados Partes, desde que prestem ou tenham prestado serviços em tais Estados Partes ${ }^{424}$.

Esse Acordo harmoniza as legislações dos países do bloco para que seus trabalhadores e familiares possam ter os direitos relativos à seguridade social garantidos quando eles imigrarem para outro país membro. Assim, por exemplo, a aposentadoria do migrante será calculada pela junção dos tempos de serviço prestados em cada um dos países membros nos quais o trabalhador tenha exercido sua atividade

422 São elas: Chuí, Santa Vitória do Palmar/Balneário do Hermenegildo e Barra do Chuí (Brasil) a Chuy, 18 de Julho, Barra de Chuy e La Coronilla (Uruguai); Jaguarão (Brasil) a Rio Branco (Uruguai); Aceguá (Brasil) a Aceguá (Uruguai); Santana do Livramento (Brasil) a Rivera (Uruguai); Quaraí (Brasil) a Artigas (Uruguai); Barra do Quaraí (Brasil) a Bella Unión (Uruguai).

423 São elas: Foz do Iguaçu a Puerto Iguazú; Capanema a Andresito, Barracão/Dionísio Cerqueira a Bernardo de Irigoyen; Porto Mauá a Alba Posse; Porto Xavier a San Javier; São Borja a Santo Tomé; Itaqui a Alvear; Uruguaiana a Paso de los Libres; Barra do Quaraí a Monte Caseros.

424 Artigo 2.2 da Acordo Multilateral de Seguridade Social do Mercado Comum do Sul. 
laboral.

O Acordo sobre Residência para Nacionais dos Estados Partes do MERCOSUL, Bolívia e Chile foi assinado em 06 de dezembro de 2002 e promulgado no Brasil pelo Decreto $n^{\circ}$ 6.975, de 07 de outubro de 2009. Ele garante que os cidadãos de quaisquer países do MERCOSUL, natos ou naturalizados há pelo menos cinco anos, terão processo simplificado para a obtenção de residência temporária por até dois anos em outro país do bloco, sem necessidade de vistos, podendo essa permissão provisória se transformar em residência permanente com a mera comprovação de meios de vida lícitos para o sustento próprio e familiar.

Além disso, o Acordo garante, na esfera trabalhista, igualdade na aplicação da legislação, além do compromisso de acordos de reciprocidade em matéria previdenciária e de inspeção imigratória e trabalhista para impedir o tráfico de pessoas. Os empregadores que contratarem imigrantes ilegais para trabalhar em suas empresas serão punidos, mas esses imigrantes terão os seus direitos resguardados em virtude do período laborado.

$\mathrm{Na}$ esfera educacional, o acordo reconhece aos filhos dos imigrantes igualdade de condições com os nacionais do país de recepção, devendo o Estado receptor prover educação gratuita às crianças, independente da regularidade da condição de residência no país. Vale ressaltar que o Acordo visa à reunificação familiar, dispondo que os Estados Partes devem conceder aos membros da família do trabalhador que sejam seus dependentes autorização de residência idêntica ao do imigrante. As exigências para obter essa residência temporária são o passaporte válido, certidão de nascimento; certidão negativa de antecedentes penais; e, dependendo do país, certificado médico da autoridade migratória.

\section{Conclusão}

Conforme exposto, o imigrante é aquele indivíduo que sai de seu país de origem buscando melhores condições de vida. $\mathrm{O}$ direito à permanência desse imigrante sempre será condicionada à soberania, cabendo discricionariamente ao Estado decidir sobre conceder ou não vistos de entrada e permanência em seu território, sendo, inclusive, que a posse do visto não garante o direito de entrada, mas é mera expectativa, podendo o indivíduo ter sua entrada negada no aeroporto se o Estado entender ser melhor para os seus interesses.

A imigração intrarregional vem aumentando consideravelmente nos últimos anos na América Latina. Hoje, segundo dados demográficos oficiais, a maior parte dos imigrantes latino-americanos prefere se estabelecer em países vizinhos. Muitas podem ser as razões, como o desenvolvimento econômico que alguns países da região, como o Brasil, vem experimentando, ou as politicas migratórias restritivas dos países industrializados, que historicamente eram os destinos preferenciais dos imigrantes da região. 
O Brasil apresenta uma posição de destaque no cenário político e econômico latino-americano, o que faz com que seja um dos principais destinos para os imigrantes provenientes da região, especialmente quando se contrasta a situação econômica de países como a Bolívia e o Paraguai, em que as situações de pobreza extrema não deixam à população outra saída senão imigrar.

A maioria dos imigrantes latino-americanos no Brasil está em situação irregular e, por isso, se encontra em condições precárias, trabalhando em situações análogas à escravidão, além de ter direitos violados diariamente. Por não terem acesso à justiça, visto que convivem com o fantasma de deportação, a situação tende a se agravar nessas comunidades, caso não sejam tomadas medidas de regulamentação por parte do Poder Público. Note-se que esses imigrantes irregulares são vítimas das políticas de restrição à imigração, tendo que se submeter a situações ilegais de trabalho, com jornadas diárias de até dezoito horas em instalações insalubres, que frequentemente também lhes servem de moradia.

A imigração de brasileiros para o exterior também é bastante expressiva, sendo que há uma muitos se dirigem para os países membros do MERCOSUL, principalmente Paraguai e Bolívia. Se a maioria desses brasileiros fica irregular nos países desenvolvidos em razão das políticas restritivas americanas e europeias, muito similares à legislação brasileira, e devido aos altos requisitos e custos para se obter o visto permanente, o mesmo não ocorre na América Latina, especialmente no subcontinente da América do Sul. Nessa região, os brasileiros estão submetidos a legislações internas e tratados regionais mais avançados em matéria de imigração, que garantem os direitos desses imigrantes. Porém, já se percebe que alguns desses países têm criados leis mais severas para os brasileiros, em razão do tratamento dispensado a seus nacionais pelo governo do Brasil.

Percebe-se que o problema consiste essencialmente no fato de que os Estados nacionais veem a imigração como potencialmente negativa, sem que haja a compreensão de que os fluxos migratórios auxiliam os países de saída, pois diminuem o índice de desemprego e o custo social, ao passo em que geram o desenvolvimento econômico dos países de entrada. Há uma tendência a adotar cada vez mais políticas para restringir a imigração, o que acaba gerando o aumento dos imigrantes irregulares. A situação desses imigrantes somente irá melhorar quando os Estados procurarem minimizar os problemas sociais e as desigualdades existentes, respeitando os seus direitos.

\section{REFERÊNCIAS}

ALBUQUERQUE, José Lindomar. Imigração em territórios fronteiriços. Anais do VI Congresso Português de Sociologia. 2008. . Disponível em: http://www.aps.pt/ vicongresso/pdfs/302.pdf. Acessado em: 20.09.2011. 
AVILA, Carlos Federico Domínguez. O Brasil diante da dinâmica migratória intra-regional vigente na América Latina e Caribe: tendências, perspectivas e oportunidades em uma nova era. Rev. bras. polít. int. [online]. 2007, vol.50, n.2, pp. 118-128. ISSN 0034-7329. Disponivel em: http:/www.scielo.br/scielo.php?pi$\mathrm{d}=$ S0034-73292007000200008\&script=sci_arttext. Acessado em: 30.04.2012.

AZEVEDO, Débora Bithiah de. Brasileiros no Exterior. 2004. Disponível em http:// bd.camara.gov.br/bd/bitstream/handle/bdcamara/2484/brasileiros_exterior_azevedo.pdf?sequence=1. Acessado em: 15.07.2011.

BAENINGER, Rosana. Brasileiros na América do Sul. CELADE/CEPAL, 2002. Disponivel em: http://www.brasileirosnomundo.itamaraty.gov.br/file/Rosana\%20 Baeninger.pdf. Acessado em: 23.10.2011.

BATISTA, Vanessa Oliveira. O fluxo migratório mundial e o paradigma contemporâneo de segurança migratória. Versus, v.3, pp.68 - 78, 2009.

BONASSI, Margherita. Canta, América Sem Fronteiras! Imigrantes latino-americanos no Brasil. São Paulo: Edições Loyola, 2000.

BONFIGLIO, Giovanni. Las migraciones internacionales como motor de desarrollo en el Perú. 2008. Disponível em: http://www.discovernikkei.org/en/journal/2008/7/1/2679/ Acessado em 20/06/2011.

BORGES, Larissa. Brasil anistia quase 42 mil estrangeiros ilegais. Terra Notícias. 2010. Disponível em: http://noticias.terra.com.br/brasil/noticias/0,,OI4190346-EI306,00-Brasil+anistia+quase+mil+estrangeiros+ilegais.html. Acessado em: 23.01.2012.

BRASIL. Lei 6.815 (1980). Estatuto do Estrangeiro. Brasília. DF, Senado, 2011.

CARMO, Maria. Cresce número de imigrantes em busca do 'sonho brasileiro'. BBC Brasil. 2008. Disponível em: http://www.bbc.co.uk/portuguese/reporterbbc/ story/2008/03/080320_imigracaoeldoradobrasil.shtml. Acessado em: 23.03.2012.

.OIM: Migração na América do Sul deve superar saida para Europa e EUA. BBC Brasil. 2012. Disponível em: http://www.bbc.co.uk/portuguese/noticias/2012/03/120319_imigracao_mc_ac.shtml. Acessado em: 23.03.2012.

CAVARZERE, Thelma Thaís. Direito Internacional da pessoa humana: a circulação internacional de pessoas, 2 ed. Rio de Janeiro: Renovar, 2001. pp. 155-157.

CAVE, Damien. Migrants'New Paths Reshaping Latin America. New York Times. 2012. Disponível em: http://www.nytimes.com/2012/01/06/world/americas/migrants-new-paths-reshaping-latin-america.html?pagewanted=all. Acessado em: 23.03.2012.

HASENBALG, Carlos; FRIGERIO, Alejandro. Imigrantes Brasileiros na Argenti- 
na: Um Perfil Sociodemográfico. 1999. Séries Estudos no 101. Disponível em: http:// www.abep.nepo.unicamp.br/docs/rev_inf/vol15_n2_1998/vol15_n2_1998_9resenha_115_118.pdf. Acessado em: 15.05.2012.

HASHIZUME, Mauricio. Escravidão é flagrada em oficina de costura ligada à Marisa. Disponível em: http://www.reporterbrasil.org.br/exibe.php?id=1714. Acessado em: 13.08.2011.

HASHIZUME, Mauricio. PYL, Bianca. Roupas da Zara são fabricadas com mão de obra escrava. Disponível em: http://www.reporterbrasil.org.br/exibe.php?id=1925. Acessado em :20.10.2011.

LOBO, Carlos; STEFANI, João; SOUSA, Guilherme. Migração na América do Sul: territorialidades e espacialidades da imigração sulamericana no Brasil. Anais do IV Encontro Nacional de Imigração. 2005. Disponível em: http://www.abep.nepo. unicamp.br/docs/anais/outros/4EncNacSobreMigracao/SCI-2.pdf. Acessado em: 20.04.2012.

LOPES, Cristiane Maria Sbalqueiro. Direito de imigração: o do estrangeiro em uma perspectiva de direitos humanos. Porto Alegre: Núria Fabris, 2009.

MELlO. Celso D. de Albuquerque. Curso de Direito Internacional Público. $13^{\mathrm{a}}$ Edição. Editora Renovar. Rio de Janeiro.São Paulo. 2001.

MINISTÉRIO DAS RELAÇÕES EXTERIORES. Brasileiros no exterior 2011. Disponível em: http://sistemas.mre.gov.br/kitweb/datafiles/BRMundo/pt-br/file/ Brasileiros\%20no\%20Mundo\%202011\%20-\%20Estimativas\%20-\%20Terceira\%20 Edi\%C3\%A7\%C3\%A3o\%20-\%20v2.pdf. Acessado em: 23.09.2011.

MINISTÉRIO DO TRABALHO E DO EMPREGO. Perfil Migratório do Brasil 2009. Disponível em http://carep.mte.gov.br/trab_estrang/perfil_migratorio_2009. pdf. Acessado em: 14.11.2010.

OLIVEIRA, Jaqueline J. S. O Brasil no Contexto das Migrações e os Direitos Humanos. estudos, Goiânia, v. 36, n. 3/4, p. 385-402, mar./abr. 2009.

PATARRA, Neide Lopes (coordenação). Migrações internacionais: Herança XX, Agenda XXI. Campinas: FNUAP; São Paulo: Oficina Editorial, 1996

, Migrações Internacionais e Migração Econômica no Cone Sul. Disponível em: www.eclac.org/Celade/proyectos/migracion/Patarra.doc. Acesso em 15 de maio de 2011.

PRENSA LATINA. Crise: América do Sul é prioridade para os novos imigrantes. 2012. Disponível em: http://www.vermelho.org.br/noticia.php?id_secao=9\&id_noticia=173351. Acessado em: 13.01.2012.

PREUSS, Ulrich K. "Migration - a Challenge to Modern Citizenship”. Constella- 
tions, v. 4, Number 3, 1008

REIS, Rossana Rocha. Soberania, Direitos Humanos e Migrações Internacionais. 2004. Revista Brasileira de Ciências Sociais volume 19 no 55, pg. 149-163. Disponivél em: http://www.scielo.br/pdf/rbcsoc/v19n55/a09v1955.pdf. Acessado em: 26.09.2010.

SOUCHAUD, Sylvain. Geografía de la migración brasileña en Paraguay. Asunción/Paraguay: UNFPA, 2002

SPRANDEL, Márcia. Anita. Brasiguaios: conflito e identidade em fronteiras internacionais. 1992. Dissertação (Mestrado). Universidade Federal do Rio de Janeiro. Rio de Janeiro.

SILVA, Sidney Antônio da. Costurando sonhos: Trajetória de um grupo de imigrantes bolivianos em São Paulo. São Paulo: Paulinas. 1997

TRINDADE, Antonio Augusto Cançado. "Human Development and Human Rights in the International Agenda of the XXIst Century", in Human Development and Human Rights Forum (August 2000), San José of Costa Rica, UNDP, 2001.

."Uprootedness and the protection of migrants in the International Law of Human Rights", Revista Brasileira de Política Internacional, v. 51, n.1, p. 137-168 (2008). 


\section{Anexos}

Anexo $A$

\begin{tabular}{|c|c|c|c|c|c|}
\hline Países & $\begin{array}{l}\text { Total de } \\
\text { estrangeiros } \\
\text { (A) }\end{array}$ & $\begin{array}{c}\text { Estrangeiros } \\
\text { latino } \\
\text { americanos }\end{array}$ & $\begin{array}{l}\text { Estrangeiros } \\
\quad \text { latino } \\
\text { americanos } \\
\text { nascidos no } \\
\quad \text { Brasil }\end{array}$ & $\begin{array}{l}\text { Estrangeiros latino } \\
\text { americanos nascidos } \\
\text { no Brasil no total de } \\
\text { estrangeiros (\%) }\end{array}$ & $\begin{array}{l}\text { Estrangeiros latino } \\
\text { americanos } \\
\text { nascidos no Brasil } \\
\text { no total de latino } \\
\text { americanos (\%) }\end{array}$ \\
\hline Argentina & 1.531 .940 & 1.011 .475 & 34.712 & 2,27 & 3,43 \\
\hline Bolívia & 87.338 & 70.794 & 14.428 & 16,52 & 20,38 \\
\hline Brasil & 683.830 & 142.018 & - & - & - \\
\hline Chile & 187.008 & 132.035 & 6.899 & 3,69 & 5,23 \\
\hline $\begin{array}{c}\text { Colômbia } \\
\text { (1996) }\end{array}$ & 106.162 & 66.505 & 1.383 & 1,3 & 2,08 \\
\hline Costa Rica & 296.461 & 43.243 & 408 & 0,14 & 0,94 \\
\hline Cuba & 15.421 & - & - & - & - \\
\hline Equador & 150.565 & 67.779 & 1.101 & 0,73 & 1,62 \\
\hline El Salvador & 26.279 & 19.321 & 181 & 0,69 & 0,94 \\
\hline Guatemala & 49.966 & 38.817 & 157 & 0,31 & 0,4 \\
\hline Haiti & 6.000 & 3.046 & - & - & - \\
\hline Honduras & 27.976 & 19.747 & 168 & 0,6 & 0,85 \\
\hline México & 487.546 & 76.994 & 2.271 & 0,47 & 2,95 \\
\hline Nicarágua & 26.043 & 20.205 & 110 & 0,42 & 0,54 \\
\hline Panamá & 82.097 & 51.397 & 790 & 0,96 & 1,54 \\
\hline Paraguai & 171.922 & 155.377 & 81.337 & 47,31 & 52,35 \\
\hline Peru & 52.725 & 23.089 & 2.523 & 4,79 & 10,93 \\
\hline R. Dominicana & 96.233 & 75.711 & 314 & 0,33 & 0,41 \\
\hline Uruguai & 92.378 & 52.867 & 13.521 & 14,64 & 25,58 \\
\hline Venezuela & 1.014 .340 & 710.569 & 4.753 & 0,47 & 0,67 \\
\hline
\end{tabular}

Fonte: Imila/Celade (2005) 
Anexo B

Participação da imigração procedente dos paises da América do Sul no total da imigraçāo da década, conforme UF de residênica no Brasil - 1991 e 2000

\begin{tabular}{|c|c|c|c|c|c|c|c|c|}
\hline \multirow{3}{*}{ UF de Residència } & \multicolumn{4}{|c|}{ América do Sul } & \multicolumn{2}{|c|}{ Demais Paises } & \multicolumn{2}{|c|}{ Total } \\
\hline & \multicolumn{2}{|c|}{1991} & \multicolumn{2}{|c|}{2000} & \multirow{2}{*}{1991} & \multirow{2}{*}{2000} & \multirow{2}{*}{1991} & \multirow{2}{*}{2000} \\
\hline & $\mathbf{N}^{0}$ & $\%$ & $\mathrm{~N}^{0}$ & $\%$ & & & & \\
\hline Rondônia & 2.275 & 91,13 & 2.030 & 85,72 & 222 & 338 & 2.497 & 2.368 \\
\hline Acre & 500 & 97,84 & 1.252 & 92,85 & 11 & 96 & 512 & 1.348 \\
\hline Amazonas & 582 & 57,36 & 2.534 & 68,72 & 432 & 1.154 & 1.014 & 3.688 \\
\hline Roraima & 817 & 88,09 & 1.426 & 80,69 & 110 & 341 & 927 & 1.767 \\
\hline Pará & 422 & 34,81 & 1.110 & 33,94 & 791 & 2.161 & 1.213 & 3.271 \\
\hline Amapá & 120 & 25,40 & 736 & 73,66 & 351 & 263 & 471 & 999 \\
\hline Tocantins & 11 & 33,98 & 165 & 44.18 & 21 & 209 & 32 & 374 \\
\hline Maranhāo & 58 & 12,06 & 321 & 55.22 & 420 & 260 & 478 & 582 \\
\hline Piaui & 0 & 0,00 & 178 & 35,53 & 202 & 324 & 202 & 502 \\
\hline Ceará & 164 & 10,46 & 399 & 11,81 & 1.401 & 2.982 & 1.565 & 3.381 \\
\hline Rio Grande do Norte & 100 & 15,63 & 254 & 15,13 & 540 & 1.423 & 640 & 1.677 \\
\hline Paraiba & 27 & 6,35 & 324 & 23,92 & 394 & 1.032 & 421 & 1.356 \\
\hline Pernambuco & 152 & 8,42 & 237 & 4,78 & 1.655 & 4.714 & 1.807 & 4.950 \\
\hline Alagoas & 65 & 15,14 & 165 & 29,29 & 365 & 398 & 430 & 563 \\
\hline Sergipe & 66 & 36,84 & 72 & 14,82 & 113 & 412 & 179 & 484 \\
\hline Bahia & 715 & 26,78 & 1.102 & 17,52 & 1.954 & 5.188 & 2.669 & 6.290 \\
\hline Minas Gerais & 1.628 & 15,81 & 2.289 & 12,27 & 8.672 & 16.364 & 10.300 & 18.654 \\
\hline Espirito Santo & 91 & 7,78 & 362 & 13,82 & 1.078 & 2.258 & 1.169 & 2.620 \\
\hline Rio de Janeiro & 3.221 & 19.96 & 5.654 & 21,16 & 12.912 & 21.063 & 16.133 & 26.717 \\
\hline São Paulo & 12.441 & 32,57 & 16.836 & 21.95 & 25.762 & 59.877 & 38.203 & 76.713 \\
\hline Paraná & 10.808 & 74,82 & 40.719 & 69,03 & 3.636 & 18.270 & 14.444 & 58.989 \\
\hline Santa Catarina & 1.798 & 53,45 & 6.652 & 57,21 & 1.566 & 4.975 & 3.364 & 11.627 \\
\hline Rio Grande do Sul & 6.619 & 65,73 & 13.269 & 63,55 & 3.451 & 7.612 & 10.070 & 20.881 \\
\hline Mato Grosso do Sul & 6.282 & 96,21 & 11.632 & 84,20 & 248 & 2.182 & 6.530 & 13.814 \\
\hline Mato Grosso & 766 & 66,26 & 3.966 & 80,24 & 390 & 977 & 1.156 & 4.943 \\
\hline Goiás & 317 & 25,84 & 710 & 14,94 & 911 & 4.039 & 1.229 & 4.749 \\
\hline Distrito Federal & 683 & 13,20 & 1.681 & 25,81 & 4.489 & 4.832 & 5.171 & 6.514 \\
\hline Total & 50.726 & 41,30 & 116.075 & 41,48 & 72.098 & 163.746 & 122.824 & 279.822 \\
\hline
\end{tabular}

Fonte: IBGE

Extraído de: http://www.abep.nepo.unicamp.br/docs/anais/outros/4EncNacSobreMigracao/SCI-2.pdf 


\section{Anexo $C$}

\begin{tabular}{|c|c|c|c|c|c|c|c|c|c|c|c|c|}
\hline \multirow{2}{*}{ Países } & \multicolumn{4}{|c|}{ Estrangeiros da Am. Latina e Caribe } & \multicolumn{4}{|c|}{$\%$ no total de latinos-americanos } & \multicolumn{4}{|c|}{$\%$ no total de estrangeiros } \\
\hline & 1970 & 1980 & 1991 & 2000 & 1970 & 1980 & 1991 & 2000 & 1970 & 1980 & 1991 & 2000 \\
\hline Argentina & 17213 & 26.633 & 25.465 & 27.531 & 23,95 & 24,1 & 21,49 & 19,09 & 1,4 & 2,4 & 3,32 & 4,03 \\
\hline Bolívia & 20712 & 12.980 & 25.694 & 20385 & 14,92 & 12,73 & 23,24 & 16,13 & 0,97 & 1,17 & 2,04 & 2,98 \\
\hline Chile & 1.900 & 17.830 & 20.437 & 17.131 & 2,65 & 16,14 & 17,24 & 11,88 & 0,15 & 2.6 & 2,65 & 2,51 \\
\hline Colômbia & $\$ 70$ & 1.490 & 2.076 & 4.159 & 2,22 & 2,35 & 1,75 & $2,8 x$ & 0,07 & 0,13 & 0,27 & 0,61 \\
\hline Costa Rica & 152 & 227 & as7 & 238 & 0,22 & 0.3 & 0,3 & 0,17 & 0,01 & 0,03 & 0,05 & 0,03 \\
\hline Cuba & 470 & 574 & 492 & 2.303 & 0,65 & 0,52 & 0,2 & 0,93 & 0,04 & 0,05 & 0.06 & 0,2 \\
\hline Equador & 357 & Tss & $\cos$ & 2.188 & as & Q69 & a.si & 0,82 & 0,03 & 0,07 & aps & 0,17 \\
\hline El Salvador & 352 & a9s & 36 & 400 & 0,49 & a.45 & ass & 0,73 & 0,03 & 0.04 & 0.05 & 0,07 \\
\hline Guatemala & 145 & 176 & $2 n$ & 158 & 0,2 & 0,16 & $a, 1$ & 0,11 & 0,01 & 0.02 & 0.02 & 0,02 \\
\hline Haiti & 90 & 227 & 141 & 15 & 0,13 & Q11 & 0.12 & 0,01 & 0,01 & 0,01 & 0,02 & 。 \\
\hline Honduras & 83 & 207 & 300 & 136 & 0,12 & Q.19 & a.2s & 0,09 & 0,01 & 0,02 & 0,04 & 0,02 \\
\hline México & 519 & 853 & 660 & 1258 & $0, \pi 2$ & 0,7 & 0,56 & 0.87 & 0,04 & 0,08 & 0,09 & 0,18 \\
\hline Nicarágua & 593 & 608 & 329 & 500 & 0,83 & ass & 0.28 & 0.35 & 0,05 & 0,05 & a.as & 0,07 \\
\hline Panamá & 371 & 641 & se1 & sss & 0,52 & 0.58 & 0.83 & 0,39 & 0,03 & 0,06 & 0,13 & 0,08 \\
\hline Paraguai & 20025 & 17.560 & 29.018 & 28.822 & 27,87 & 15,89 & 16,05 & 19,99 & 1,63 & 1,58 & 2,48 & 4,21 \\
\hline Peru & 2.410 & 3.789 & 5.833 & 20814 & 3,36 & 3,43 & 4,92 & 7,5 & 0,2 & 0,34 & 0,76 & 1,58 \\
\hline R. Dominicana & 221 & 169 & 178 & 102 & 0,32 & a,1s & 0,15 & 0,07 & 0,02 & 0,02 & 0,02 & 0,01 \\
\hline Uruguai & 13.582 & 22.238 & 22.141 & 24.700 & 18,92 & 29,21 & 2868 & 17,15 & 1,12 & 1,91 & 2,88 & 3,62 \\
\hline Venezuela & 989 & 1.262 & 2.226 & 2.162 & 1,38 & 2,24 & 2,03 & 2,5 & 0,00 & 0,12 & 0,16 & 0,32 \\
\hline Barbados & $\cdot$ & $\cdot$ & $\cdot$ & - & - & - & $\cdot$ & - & $\cdot$ & - & - & - \\
\hline Belize & 82 & 40 & 220 & - & 0,12 & aos & a. & - & 0,01 & 0 & 002 & • \\
\hline Guiana & 364 & 606 & 2.131 & 2.603 & 0,52 & 263 & 0,95 & 2,11 & 0,03 & 0,06 & 0.15 & 0,23 \\
\hline Guiana Francesa & 116 & 1.759 & 651 & 623 & 0,16 & 2,59 & ass & 0,43 & 0.01 & 0,16 & 0,08 & 0.09 \\
\hline Jamaica & $s=$ & 89 & 11 & 57 & 0,08 & 0,08 & $\infty 01$ & 0,04 & ○ & 0,02 & 0 & 0,01 \\
\hline Suriname & 160 & 296 & 291 & 232 & 0,22 & 0,18 & 0.16 & 0,16 & 0,01 & 0,02 & 002 & 0,03 \\
\hline \begin{tabular}{|l} 
Trinidad e \\
Tobago
\end{tabular} & 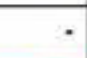 & $\cdot$ & $\cdot$ & • & • & • & $\cdot$ & 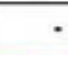 & - & 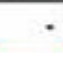 & - & \\
\hline
\end{tabular}

Fonte: CELADE 
Anexo D

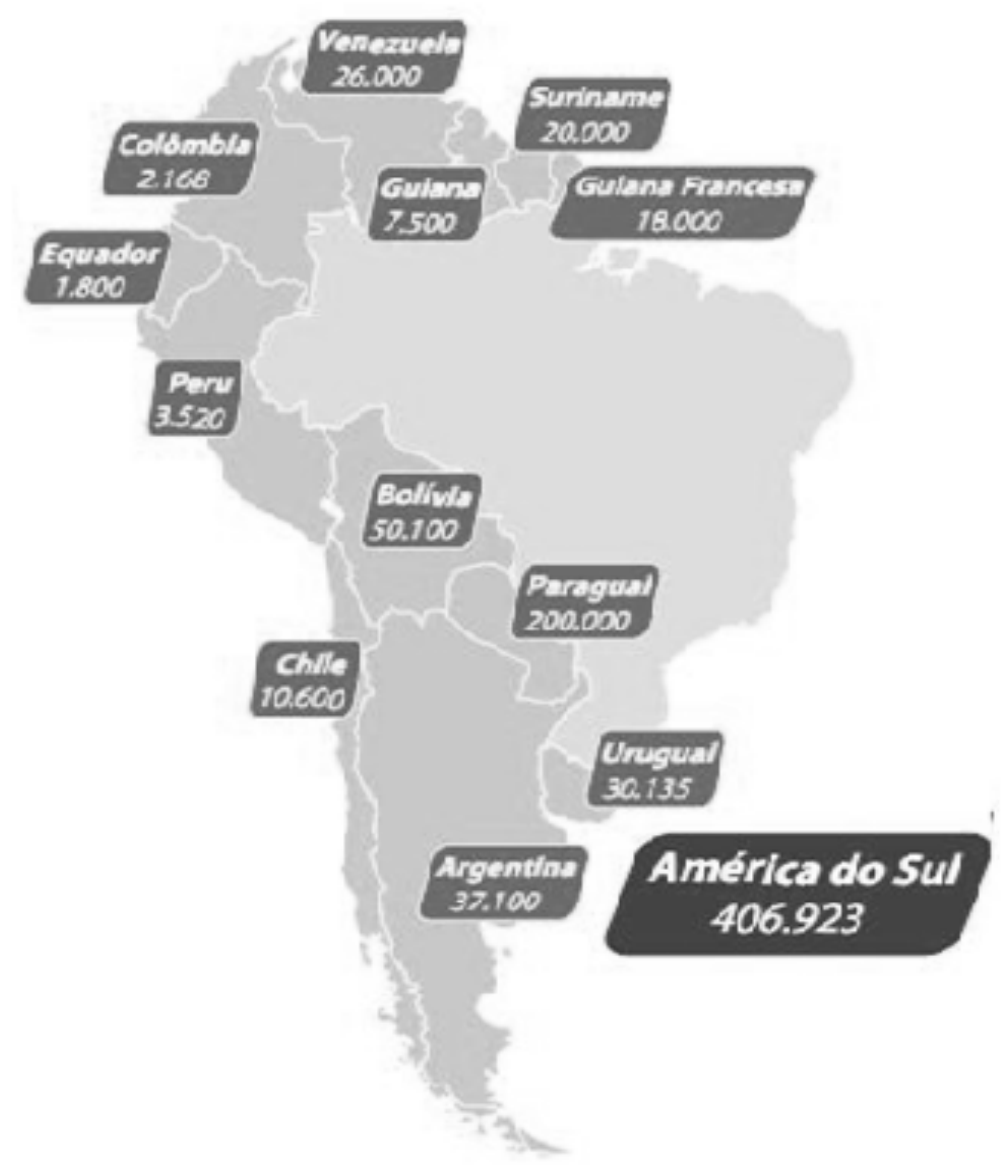

Fonte: Ministério das Relações Exteriores 